\title{
Competencias digitales de docentes de educación secundaria en una provincia del centro del Perú
}

\author{
Digital Competences in Secondary Education Teachers in a Province of Central Peru \\ Competências digitais de professores da educação do ensino médio em uma província no \\ centro do Peru
}

Jhon Richard Orosco-Fabian

Universidad Nacional del Centro del Perú

Tarma, Perú

jorosco@uncp.edu.pe

(iD) https://orcid.org/0000-0001-9035-706X

Rocío Pomasunco-Huaytalla

Universidad Nacional del Centro del Perú

Tarma, Perú

rpomasunco@uncp.edu.pe

(iD) https://orcid.org/0000-0002-8656-1479

Wilfredo Gómez-Galindo

Universidad Nacional del Centro del Perú

Tarma, Perú

wgomez@uncp.edu.pe

(D) https://orcid.org/0000-0002-9946-0538

Edwin Salgado-Samaniego

Universidad Nacional del Centro del Perú

Tarma, Perú

esalgado@uncp.edu.pe

(D) https://orcid.org/0000-0002-4473-479X

Deysi Alina Colachagua-Calderón Universidad Nacional del Centro del Perú

Tarma, Perú deysic91@hotmail.com

https://orcid.org/0000-0003-0274-5658

Recibido • Received • Recebido: 28 / 12 / 2019

Corregido • Revised • Revisado: 21 / 07 / 2021

Aceptado • Accepted • Aprovado: 25 / 08 / 2021 
http://doi.org/10.15359/ree.25-3.34

http://www.una.ac.cr/educare

educare@una.ac.cr

\begin{abstract}
Resumen:
Objetivo: Analizar el nivel de logro de las competencias digitales de docentes del nivel secundario según sexo, edad y condición laboral. Metodología: La investigación es de enfoque cuantitativo, de diseño transversal descriptivo. La muestra estuvo compuesta por 247 docentes de las instituciones educativas públicas de una provincia de la región central del Perú. Se recogió información a través de un instrumento elaborado con base en la propuesta del Instituto Nacional de Tecnologías Educativas y de Formación del Profesorado (Intef, 2017) que evalúa competencias digitales agrupadas en cinco áreas. Resultados: Los resultados muestran que el personal docente presenta un nivel de logro satisfactorio en las competencias digitales de: navegación, búsqueda y filtrado de información, datos y contenidos digitales $(50,2 \%)$, desarrollo de contenidos digitales $(42,5 \%)$, integración curricular $(46,2 \%)$ y protección de la salud $(44,9 \%)$ y en las demás competencias digitales se evidencia un nivel de logro en proceso. Conclusión: El personal docente está en proceso de desarrollo de las competencias digitales, y existe diferencia significativa en cuanto a las variables sexo, edad y condición laboral.
\end{abstract}

Palabras claves: Competencia; digital; docente; educación; tecnología.

\begin{abstract}
:
Objective: Analyze the level of achievement of digital competencies in secondary education teachers according to gender, age, and working conditions. Method: The research has a quantitative approach and a descriptive cross-sectional design. The sample consisted of 247 teachers from public educational institutions of a province in the central region of Peru. Information was collected through an elaborated instrument based on the proposal of the Intef (2017) that assesses digital competencies grouped into five areas. Results: The results show that teachers have a satisfactory level of achievement in the digital competencies of Internet navigation, search and filtering of information, data and digital content (50.2\%), development of digital content (42.5\%), curriculum integration (46.2\%), and health protection (44.9\%). In the other digital competencies, teachers have a level of achievement in progress. Conclusions: It is concluded that teachers are in the process of developing digital competencies, and there is a significant difference in relation to the variables of gender, age, and working conditions.
\end{abstract}

Keywords: Competence; digital; teacher; education; technology.

\title{
Resumo:
}

Objetivo: Analisar o nível de realização das competências digitais de professores do ensino médio de acordo com sexo, idade e condição de trabalho. Metodologia: A pesquisa é de abordagem quantitativa, desenho transversal descritivo. A amostra foi composta por 247 professores de instituições educacionais públicas de uma província da região central do Peru. As informações foram coletadas por meio de um instrumento elaborado com base na proposta do Intef (2017) que avalia as competências digitais agrupadas em cinco áreas. Resultados: Os resultados mostram que os docentes têm um nível satisfatório de desempenho nas competências digitais de: navegação, pesquisa e filtragem de informações, dados e conteúdo digital (50,2\%), desenvolvimento de conteúdo digital $(42,5 \%)$, integração curricular $(46,2 \%)$ e proteção à saúde $(44,9 \%)$ e nas demais competências digitais é evidente um nível de realizações em andamento. Conclusão: conclui-se que o corpo docente está em processo de desenvolvimento de competências digitais, e há uma diferença significativa em termos das variáveis sexo, idade e condição de trabalho.

Palavras-chave: Competência; digital; professor; educação; tecnologia. 


\section{Introducción}

Actualmente, las tecnologías de la información y comunicación (TIC) han modificado diferentes actividades, han transformado los sistemas educativos, específicamente al introducir las TIC en los espacios de aprendizaje. El estudiantado entiende sobre el manejo de equipos, programas, recursos, aplicativos entre otros; sin embargo, la incorporación de recursos digitales requiere docentes con una formación en competencias digitales (Arbués et al., 2014).

El acceso a la información ha evolucionado gracias a la digitalización, así también se han transformado las formas de procesamiento, almacenamiento y la transmisión de información (Vivancos, 2008). En la interacción de estudiantes y docentes se aprecia que los primeros sefamiliarizan rápidamente con los recursos digitales; por el contrario, los segundos, muestran rechazo, sin embargo, esto está cambiando por las exigencias de las políticas educativas (Benítez Larghi et al., 2014).

Al analizar la problemática a nivel internacional, en España, Pozuelo Echegaray (2014) identificó que el personal docente más capacitado tecnológicamente incorporan el uso de las TIC con mayor frecuencia, además proponen cambios, y promueven las competencias TIC en sus estudiantes. También, González Rivallo y Gutiérrez Martín (2017) identificaron que la integración curricular de las tecnologías digitales en el aula es todavía escasa e inadecuada. Por otro lado, Falcó Boudet (2017) señala que el personal docente muestra una actitud positiva hacia el uso de las TIC, pero son pocos los que las aprovechan. García-Pérez et al. (2016) encontraron que el personal docente presenta un nivel moderado de competencia digital (CD) en el uso de redes sociales, además no encontraron diferencias significativas en cuanto a género, pero sí en función de la edad.

En el contexto latinoamericano, en México, Mortis Lozoya et al. (2013) hallaron que los docentes y las docentes son competentes en aspectos instrumentales y cognitivos más no en lo didáctico-metodológico. Además, que existe diferencia entre las edades. En Colombia, Hernández Suárez et al. (2016) identificaron que el personal docente está entre competente y muy competente. En Chile, el futuro profesorado accede a diversos recursos tecnológicos, por ello se deduce que son sujetos nativos digitales, pero la deficiencia es que no conocen, ni emplean estas competencias con una orientación didáctica en el aula (Sandoval Rubilar et al., 2017). En la capital del Perú, Guizado Osco et al. (2019) encontraron que el 78\% del personal docente presenta un nivel regular, y el $22 \%$ un buen nivel de competencias digitales.

En Ecuador, se ha implementado las escuelas con pizarras digitales interactivas (PDI), pero, según Castillo Obaco et al. (2016), el personal docente presenta un nivel bajo en el conocimiento y su uso, aunque reconocen las ventajas. En México, Talanquer (2009) afirma que cuando se empleen las TIC para crear modelos, investigar, resolver problemas y sean sujeto de las evaluaciones, más maestros, maestras y estudiantes estarán dispuestos a invertir el tiempo y esfuerzo en desarrollar competencias digitales. En Colombia, Escorcia-Oyola y Jaimes de Triviño (2015) consideran que se deben afianzar programas de formación docente que incluyan las tecnologías y se construyan redes de aprendizajes empleando las TIC como medios educativos. 
http://doi.org/10.15359/ree.25-3.34

http://www.una.ac.cr/educare

educare@una.ac.cr

En las escuelas latinoamericanas el uso de las TIC ha fortalecido los contextos de aprendizaje en cuatro niveles (alumnado, aula, escuela, país); al respecto, Román y Murillo (2014, p. 879) realizaron este estudio en dieciséis países de América Latina, incluyendo casi a 91000 estudiantes y más de 3000 docentes, en dicho estudio:

se constata que un estudiante que cuente con una computadora en su hogar, que [vaya] a una escuela con más de diez computadoras, que los utilice al menos una vez por semana y tenga un profesor/a que use habitualmente la computadora en su casa, obtendrá un desempeño significativamente más alto en ambas áreas evaluadas: 23 puntos más en matemáticas y 25 en lectura.

Así también, en la capital de Perú, Vargas D’Uniam et al. (2014) identificaron las competencias tecnológicas básicas, pedagógicas y tecnológicas complejas, encontraron mayor presencia de las primeras. Las competencias digitales en docentes de educación básica es tema de interés a nivel internacional, porque el estudiantado de hoy pertenece a una nueva generación, así lo explican Fernández-Cruz y Fernández-Díaz (2016), al abordar acerca del personal docente de la generación $Z$ y sus competencias digitales, dejan claro que existe una laguna importante en la formación del personal docente en el uso de las TIC y su aplicación.

Se han realizado una serie de aportes de desarrollo de competencias digitales en el personal docente, así es que Rangel Baca (2015) propone un perfil de competencias docentes digitales con base en las dimensiones tecnológica, informacional y pedagógica. También Pinto Santos et al. (2016, p. 40) plantean un modelo espiral de competencias docentes, según ello "el docente a partir de procesos de formación construccionista en tecnología educativa va transformando de manera espiral las formas como usa las TIC, para apropiarlas como TAC y finalmente como TEP". En la interacción docente y estudiante, se requieren de competencias digitales, sobre todo por parte del personal docente. Cabe mencionar que existen varias propuestas de perfil de competencias y que en esta investigación se ha tomado la del Instituto Nacional de Tecnologías Educativas y de Formación del Profesorado (Intef, 2017) que propone las competencias digitales agrupadas en cinco áreas:

Área de competencia 1. Información y alfabetización informacional: (1) Navegación, búsqueda y filtrado de información, datos y contenidos digitales. (2) Evaluación de información, datos y contenidos digitales. (3) Almacenamiento y recuperación de información, datos y contenidos digitales.

Área de competencia 2. Comunicación y colaboración: (1) Interacción mediante las tecnologías digitales. (2) Compartir información y contenidos digitales. (3) Participación ciudadana en línea. (4) Colaboración mediante canales digitales. (5) Netiqueta. (6) Gestión de la identidad digital. 
http://doi.org/10.15359/ree.25-3.34

Área de competencia 3. Creación de contenidos digitales: (1) Desarrollo de contenidos digitales. (2) Integración y reelaboración de contenidos digitales. (3) Derechos de autor y licencias. (4) Programación.

Área de competencia 4. Seguridad: (1) Protección de dispositivos. (2) Protección de datos personales e identidad digital. (3) Protección de la salud. (4) Protección del entorno.

Área de competencia 5. Resolución de problemas: (1) Resolución de problemas técnicos. (2) Identificación de necesidades y respuestas tecnológicas. (3) Innovación y uso de la tecnología digital de forma creativa. (4) Identificación de lagunas en la competencia digital. (p. 2)

En el contexto peruano, no hay un marco específico de las competencias digitales del docente de educación básica regular, además que no hay muchos estudios publicados en revistas científicas, ello motivó a realizar el estudio en el contexto de la región central del Perú, por ello esta investigación tiene como objetivo: Analizar el nivel del logro del área de competencia digital docente de información y alfabetización informacional, comunicación y colaboración, creación de contenidos digitales, seguridad y resolución de problemas según sexo, edad y condición laboral.

\section{Método}

Participantes: La muestra se conformó por 247 docentes del nivel secundario de instituciones educativas públicas de una provincia de la región central del Perú. La muestra fue representativa con un nivel de confianza del 95\%. En la Tabla 1 se consideran las características.

Tabla 1: Características de la muestra

\begin{tabular}{|c|c|c|}
\hline Sexo & $f$ & $\%$ \\
\hline Varón & 159 & 64.4 \\
\hline Mujer & 88 & 35.6 \\
\hline Edad & $f$ & $\%$ \\
\hline 20 a 30 años & 11 & 4.5 \\
\hline 31 a 40 años & 74 & 30.0 \\
\hline 41 a 50 años & 99 & 40.1 \\
\hline 51 años a más & 63 & 25.5 \\
\hline Condición laboral & $f$ & $\%$ \\
\hline Nombrado & 119 & 48.2 \\
\hline Contratado & 128 & 51.8 \\
\hline
\end{tabular}

Nota: Elaboración propia. 
http://doi.org/10.15359/ree.25-3.34

http://www.una.ac.cr/educare

educare@una.ac.cr

Instrumento: El instrumento denominado Cuestionario de competencias digitales en docentes de educación secundaria se elaboró con base en Intef (2017). Se tomaron en consideración las 21 competencias dentro de las cinco áreas que lo componen, también se agregó la competencia integración curricular dentro del área creación de contenidos digitales, finalmente 22 competencias conforman el estudio. Para determinar la validez del instrumento se realizó a través del coeficiente de validez de contenido (CVC) desarrollado por Hernández Nieto (2011); se obtuvo 0,82. Respecto a la fiabilidad, la puntuación del alfa de Cronbach del instrumento es de 0,97 . El cuestionario contiene preguntas relacionadas a las características sociodemográficas (sexo, edad y condición laboral) y a las competencias digitales, cada una tiene tres ítems lo cual hace un total de 66 que conforman el instrumento distribuidas en 22 competencias digitales. La escala del instrumento se basó en los cuatro niveles de logro de la evaluación del marco del buen desempeño docente: insatisfactorio, en proceso, satisfactorio y destacado (Ministerio de Educación, 2017).

Procedimiento: Para la aplicación del instrumento se solicitó permiso a las personas directoras de las instituciones educativas públicas seleccionadas. Después de la autorización correspondiente, se aplicó el cuestionario impreso en papel a aquel personal docente que accedió a participar voluntariamente, no sin antes explicarles el objetivo del estudio y la confidencialidad de las respuestas. Los datos fueron recogidos en los meses de junio, julio y agosto del año 2019.

Análisis estadístico: En cuanto al análisis de datos, las variables cualitativas se presentan según su distribución de frecuencias y porcentajes. Se han realizado análisis no paramétricos después de comprobar el incumplimiento de los supuestos de normalidad, para analizar las diferencias de la variable sexo y condición laboral se llevó a cabo la prueba U de Mann-Whitney y para la variable edad se utilizó la prueba Kruskal-Wallis porque presentan más de dos valores de respuesta. Las diferencias son consideradas significativas a partir de $p<.05$.

\section{Resultados}

De la competencia digital 1 (Tabla 2), en el 50,2\% (124) de docentes prevalece el logro satisfactorio; $34,0 \%$ (84) son varones y $16,2 \%$ (40) mujeres sin diferencia significativa (U= $6160.500, p=.088)$. En relación con la edad también hay mayor frecuencia en el mismo nivel de logro, el 19,4\% (48) de docentes entre 41 a 50 años de edad, con diferencia significativa $(\mathrm{H}=9.729, p=.021)$. En relación con la condición laboral el 20,6\% (51) de docentes con nombramiento y el $29.6 \%$ (73) con contratos tienen un logro satisfactorio, con diferencia significativa $(U=6303.500, p=.010)$. 
Tabla 2: Área de competencia digital docente de información y alfabetización informacional

\begin{tabular}{|c|c|c|c|c|c|c|c|}
\hline \multirow{2}{*}{\multicolumn{3}{|c|}{ Área de competencia 1}} & \multirow{2}{*}{$\begin{array}{c}\text { Insatisfactorio } \\
f(\%)\end{array}$} & \multirow{2}{*}{$\begin{array}{c}\text { En proceso } \\
\mathbf{f}(\%)\end{array}$} & \multirow{2}{*}{$\begin{array}{c}\text { Satisfactorio } \\
\mathbf{f}(\%)\end{array}$} & \multirow{2}{*}{$\begin{array}{c}\text { Destacado } \\
\mathbf{f}(\%)\end{array}$} & \multirow{2}{*}{$p$} \\
\hline & & & & & & & \\
\hline \multirow{9}{*}{ 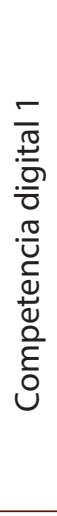 } & \multirow{2}{*}{ Sexo } & Varón & $9(3.6)$ & $48(19.4)$ & $84(34.0)$ & $18(7.3)$ & \multirow{2}{*}{.088} \\
\hline & & Mujer & $3(1.2)$ & $39(15.8)$ & $40(16.2)$ & $6(2.4)$ & \\
\hline & \multirow{4}{*}{ Edad } & $20-30$ & $2(0.8)$ & $1(0.4)$ & $7(2.8)$ & $1(0.4)$ & \multirow{4}{*}{.021} \\
\hline & & $31-40$ & $2(0.8)$ & $19(7.7)$ & $46(18.6)$ & $7(2.8)$ & \\
\hline & & $41-50$ & $1(0.4)$ & $39(15.8)$ & $48(19.4)$ & $11(4.5)$ & \\
\hline & & $>50$ & $7(2.8)$ & $28(11.3)$ & $23(9.3)$ & $5(2.0)$ & \\
\hline & \multirow{2}{*}{ Condición laboral } & Nombrado & $8(3.2)$ & $50(20.2)$ & $51(20.6)$ & $10(4.0)$ & \multirow{2}{*}{.010} \\
\hline & & Contratado & $4(1.6)$ & $37(15.0)$ & $73(29.6)$ & $14(5.7)$ & \\
\hline & \multicolumn{2}{|c|}{ Total CD1 } & $12(4.9)$ & $87(35.2)$ & $124(50.2)$ & $24(9.7)$ & \\
\hline \multirow{9}{*}{ 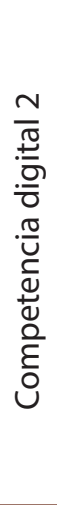 } & \multirow{2}{*}{ Sexo } & Varón & $9(3.6)$ & $63(25.5)$ & $80(32.4)$ & $7(2.8)$ & \multirow{2}{*}{.000} \\
\hline & & Mujer & $12(4.9)$ & $53(21.5)$ & 19(7.7) & $4(1.6)$ & \\
\hline & \multirow{4}{*}{ Edad } & $20-30$ & $0(0.0)$ & $5(2.0)$ & $5(2.0)$ & $1(0.4)$ & \multirow{4}{*}{.065} \\
\hline & & $31-40$ & $6(2.4)$ & $28(11.3)$ & $35(14.2)$ & $5(2.0)$ & \\
\hline & & $41-50$ & $5(2.0)$ & $52(21.1)$ & $39(15.8)$ & $3(1.2)$ & \\
\hline & & $>50$ & $10(4.0)$ & $31(12.6)$ & $20(8.1)$ & $2(0.8)$ & \\
\hline & \multirow{2}{*}{ Condición laboral } & Nombrado & $13(5.3)$ & $57(23.1)$ & $43(17.4)$ & $6(2.4)$ & \multirow{2}{*}{.250} \\
\hline & & Contratado & $8(3.2)$ & $59(23.9)$ & $56(22.7)$ & $5(2.0)$ & \\
\hline & \multicolumn{2}{|c|}{ Total CD2 } & $21(8.5)$ & $116(47.0)$ & $99(40.1)$ & $11(4.5)$ & \\
\hline \multirow{10}{*}{ 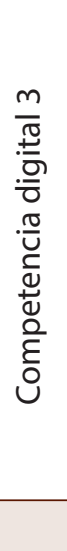 } & \multirow{2}{*}{ Sexo } & Varón & $16(6.5)$ & $59(23.9)$ & $75(30.4)$ & $9(3.6)$ & \multirow{2}{*}{.001} \\
\hline & & Mujer & $10(4.0)$ & $54(21.9)$ & $21(8.5)$ & $3(1.2)$ & \\
\hline & \multirow{4}{*}{ Edad } & $20-30$ & $1(0.4)$ & $5(2.0)$ & $4(1.6)$ & $1(0.4)$ & \multirow{4}{*}{.001} \\
\hline & & $31-40$ & $6(2.4)$ & $24(9.7)$ & $39(15.8)$ & $5(2.0)$ & \\
\hline & & $41-50$ & $6(2.4)$ & $52(21.1)$ & $35(14.2)$ & $6(2.4)$ & \\
\hline & & $>50$ & $13(5.3)$ & $32(13.0)$ & $18(7.3)$ & $0(0.0)$ & \\
\hline & \multirow{2}{*}{ Condición laboral } & Nombrado & $13(5.3)$ & $63(25.5)$ & $37(15.0)$ & $6(2.4)$ & \multirow{2}{*}{.061} \\
\hline & & Contratado & $13(5.3)$ & $50(20.2)$ & $59(23.9)$ & $6(2.4)$ & \\
\hline & \multicolumn{2}{|c|}{ Total CD3 } & $26(10.5)$ & $113(45.7)$ & $96(38.9)$ & $12(4.9)$ & \\
\hline & Total área de comp & ncia 1 & $10(4.0)$ & $119(48.2)$ & $111(44.9)$ & $7(2.8)$ & \\
\hline
\end{tabular}

Nota: Competencia digital 1 = Navegación, búsqueda y filtrado de información, datos y contenidos digitales. Competencia digital 2 = Evaluación de información, datos y contenidos digitales. Competencia digital $3=$ Almacenamiento y recuperación de información, datos y contenidos digitales. 
http://doi.org/10.15359/ree.25-3.34

http://www.una.ac.cr/educare

educare@una.ac.cr

En cuanto a la competencia digital 2 (Tabla 2), el 47,0\% (116) de docentes presenta un nivel de logro en proceso. Cuando analizamos por sexo el 32,4\% (80) de varones presenta un logro satisfactorio y el $21,5 \%$ (53) de mujeres señala logro en proceso, habiendo diferencia significativa $(U=4950.500, p=$ .000). En relación con la edad se encontró que en el 21,1\% (52) de docentes de 41 a 50 años presenta logro en proceso, no habiendo diferencia significativa $(\mathrm{H}=7.218, p=.065)$. De la variable condición laboral el $23,1 \%$ (57) de docentes con nombramiento y $23,9 \%$ (59) de docentes con contrato señalan que su nivel de logro está en proceso, no habiendo diferencia significativa $(U=7027.500, p=.250)$.

De la competencia digital 3 (Tabla 2), el 45,7\% (113) de docentes tiene un logro en proceso. Cuando analizamos por sexo el 30,4\% (75) de varones tiene un logro satisfactorio y en el caso de las mujeres el $21,9 \%(54)$ está en proceso, con diferencia significativa ( $U=5363.000, p=.001)$. En relación con la edad, el 21,1\% (52) de docentes de 41 a 50 años tiene nivel de logro en proceso, habiendo diferencia significativa $(H=15.897, p=.001)$. De la condición laboral, el 25,5\% (63) de docentes con nombramiento tiene un logro en proceso y el $23,9 \%$ (59) de docentes con contrato tiene logro satisfactorio, sin diferencia significativa $(U=6651.000, p=.061)$.

Finalmente, el personal docente presenta un nivel de logro satisfactorio en la competencia navegación, búsqueda y filtrado de información, datos y contenidos digitales; y un nivel de logro en proceso de las competencias evaluación y almacenamiento y recuperación de información, datos y contenidos digitales. Analizando a nivel de área, el 48,2\% (119) de docentes está en proceso de desarrollar el área de competencia digital docente referido a la información y alfabetización informacional.

Tabla 3: Área de competencia digital docente de comunicación y colaboración

\begin{tabular}{|c|c|c|c|c|c|c|c|}
\hline & f́ma decrmnoto & ? & Insatisfactorio & En proceso & Satisfactorio & Destacado & \\
\hline & 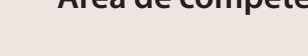 & 1a 2 & $f(\%)$ & $f(\%)$ & $f(\%)$ & $f(\%)$ & P \\
\hline & & Varón & $22(8.9)$ & $74(30.0)$ & $56(22.7)$ & $7(2.8)$ & 110 \\
\hline & sexo & Mujer & 19(7.7) & $35(14.2)$ & $30(12.1)$ & $4(1.6)$ & 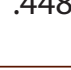 \\
\hline$\frac{\nabla}{ \pm}$ & & $20-30$ & $1(0.4)$ & $4(1.6)$ & $5(2.0)$ & $1(0.4)$ & \\
\hline 흠 & Fdad & $31-40$ & $10(4.0)$ & $27(10.9)$ & $31(12.6)$ & $6(2.4)$ & \\
\hline 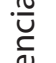 & Luad & $41-50$ & $14(5.7)$ & 49(19.8) & $33(13.4)$ & $3(1.2)$ & .021 \\
\hline ֻั & & $>50$ & $16(6.5)$ & $29(11.7)$ & $17(6.9)$ & $1(0.4)$ & \\
\hline రั & Condición Jaboral & Nombrado & $17(6.9)$ & $59(23.9)$ & $39(15.8)$ & $4(1.6)$ & 673 \\
\hline & & Contratado & $24(9.7)$ & $50(20.2)$ & $47(19.0)$ & $7(2.8)$ & \\
\hline & Total C & & $41(16.6)$ & 109(44.1) & $86(34.8)$ & $11(4.5)$ & \\
\hline
\end{tabular}




\begin{tabular}{|c|c|c|c|c|c|c|c|}
\hline & \multirow{2}{*}{\multicolumn{2}{|c|}{ Área de competencia 2}} & Insatisfactorio & En proceso & Satisfactorio & Destacado & \multirow{2}{*}{$p$} \\
\hline & & & $f(\%)$ & $f(\%)$ & $f(\%)$ & $f(\%)$ & \\
\hline \multirow{9}{*}{ 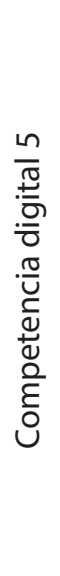 } & \multirow{2}{*}{ Sexo } & Varón & $14(5.7)$ & $70(28.3)$ & $67(27.1)$ & $8(3.2)$ & \multirow{2}{*}{.000} \\
\hline & & Mujer & $21(8.5)$ & $42(17.0)$ & $23(9.3)$ & $2(0.8)$ & \\
\hline & \multirow{4}{*}{ Edad } & $20-30$ & $0(0.0)$ & $6(2.4)$ & $5(2.0)$ & $0(0.0)$ & \multirow{4}{*}{.108} \\
\hline & & $31-40$ & $6(2.4)$ & $35(14.2)$ & $29(11.7)$ & $4(1.6)$ & \\
\hline & & $41-50$ & $15(6.1)$ & $42(17.0)$ & $36(14.6)$ & $6(2.4)$ & \\
\hline & & $>50$ & $14(5.7)$ & $29(11.7)$ & $20(8.1)$ & $0(0.0)$ & \\
\hline & \multirow{2}{*}{ Condición laboral } & Nombrado & $17(6.9)$ & $59(23.9)$ & $38(15.4)$ & $5(2.0)$ & \multirow{2}{*}{.313} \\
\hline & & Contratado & $18(7.3)$ & $53(21.5)$ & $52(21.1)$ & $5(2.0)$ & \\
\hline & \multicolumn{2}{|c|}{ Total CD5 } & $35(14.2)$ & $112(45.3)$ & $90(36.4)$ & $10(4.0)$ & \\
\hline \multirow{9}{*}{ 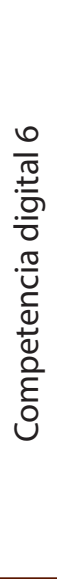 } & \multirow{2}{*}{ Sexo } & Varón & $23(9.3)$ & $74(30.0)$ & $53(21.5)$ & $9(3.6)$ & \multirow{2}{*}{.000} \\
\hline & & Mujer & $28(11.3)$ & $42(17.0)$ & $15(6.1)$ & $3(1.2)$ & \\
\hline & \multirow{4}{*}{ Edad } & $20-30$ & $2(0.8)$ & $6(2.4)$ & $2(0.8)$ & $1(0.4)$ & \multirow{4}{*}{.000} \\
\hline & & $31-40$ & $6(2.4)$ & $32(13.0)$ & $30(12.1)$ & $6(2.4)$ & \\
\hline & & $41-50$ & $23(9.3)$ & 47(19.0) & $25(10.1)$ & $4(1.6)$ & \\
\hline & & $>50$ & $20(8.1)$ & $31(12.6)$ & $11(4.5)$ & $1(0.4)$ & \\
\hline & \multirow{2}{*}{ Condición laboral } & Nombrado & $28(11.3)$ & $61(24.7)$ & $25(10.1)$ & $5(2.0)$ & \multirow{2}{*}{.035} \\
\hline & & Contratado & $23(9.3)$ & $55(22.3)$ & $43(17.4)$ & $7(2.8)$ & \\
\hline & \multicolumn{2}{|c|}{ Total CD6 } & $51(20.6)$ & 116(47.0) & $68(27.5)$ & $12(4.9)$ & \\
\hline \multirow{9}{*}{ 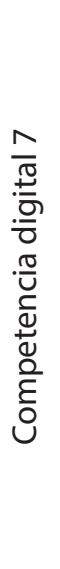 } & \multirow{2}{*}{ Sexo } & Varón & $41(16.6)$ & $56(22.7)$ & $55(22.3)$ & $7(2.8)$ & \multirow{2}{*}{.002} \\
\hline & & Mujer & $36(14.6)$ & $35(14.2)$ & $13(5.3)$ & $4(1.6)$ & \\
\hline & \multirow{4}{*}{ Edad } & $20-30$ & $2(0.8)$ & $5(2.0)$ & $3(1.2)$ & $1(0.4)$ & \multirow{4}{*}{.000} \\
\hline & & $31-40$ & $12(4.9)$ & $26(10.5)$ & $30(12.1)$ & $6(2.4)$ & \\
\hline & & $41-50$ & $32(13.0)$ & $43(17.4)$ & $21(8.5)$ & $3(1.2)$ & \\
\hline & & $>50$ & $31(12.6)$ & $17(6.9)$ & $14(5.7)$ & $1(0.4)$ & \\
\hline & \multirow{2}{*}{ Condición laboral } & Nombrado & $43(17.4)$ & $48(19.4)$ & $22(8.9)$ & $6(2.4)$ & \multirow{2}{*}{.017} \\
\hline & & Contratado & $34(13.8)$ & $43(17.4)$ & $46(18.6)$ & $5(2.0)$ & \\
\hline & \multicolumn{2}{|c|}{ Total CD7 } & $77(31.2)$ & $91(36.8)$ & $68(27.5)$ & $11(4.5)$ & \\
\hline
\end{tabular}


http://doi.org/10.15359/ree.25-3.34

http://www.una.ac.cr/educare

educare@una.ac.cr

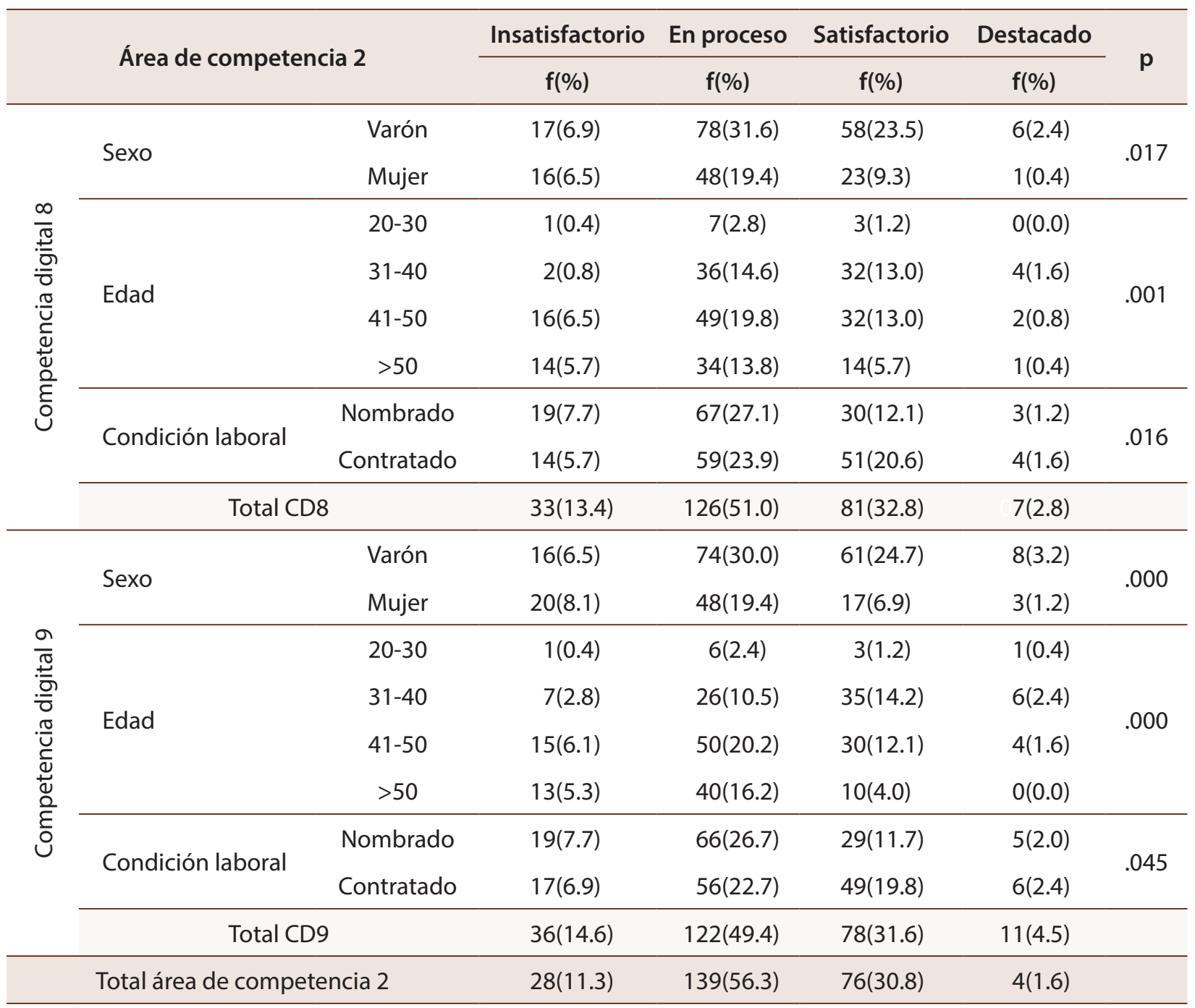

Nota: Competencia digital 4 = Interacción mediante las tecnologías digitales. Competencia digital $5=$ Compartir información y contenidos digitales. Competencia digital 6 = Participación ciudadana en línea. Competencia digital $7=$ Colaboración mediante canales digitales. Competencia digital $8=$ Netiqueta. Competencia digital $9=$ Gestión de la identidad digital.

De la competencia digital 4 (Tabla 3), el 44,1\% (109) de docentes evidencia logro en proceso; $30,0 \%$ (74) son varones y $14,2 \%$ (35) mujeres sin diferencia significativa $(U=6616.000, p=.448)$. Cuando analizamos la edad también predomina el logro en proceso, siendo el $19,8 \%$ (49) de docentes de 41 a 50 años de mayor frecuencia, habiendo diferencia significativa $(H=9.729, p=$ .021). En relación con la condición laboral el $23,9 \%$ (59) de docentes nombrados o nombradas y el 20,2\% (50) de docentes con contratación presentan logro en proceso, no habiendo diferencia significativa $(U=7395.500, p=.673)$. 
http://doi.org/10.15359/ree.25-3.34

En cuanto a la competencia digital 5 (Tabla 3), en el 45,3\% (112) de docentes prevalece el logro en proceso, de este grupo $28,3 \%$ (70) son varones y $17,0 \%$ (42) mujeres con diferencia significativa $(U=5217.500, p=.000)$. En relación con la edad también se encontró mayor frecuencia en el mismo nivel de logro, siendo el 17,0\% (42) entre 41 a 50 años de edad, no habiendo diferencia significativa $(H=6.084, p=.108)$. De la variable condición laboral el $23,9 \%$ (59) de docentes con nombramiento y $21,5 \%$ (53) de docentes con contrato tienen logro en proceso, no habiendo diferencia significativa $(U=7092.000, p=.313)$.

De la competencia digital 6 (Tabla 3), el 47,0\% (116) de docentes presenta logro en proceso, $30,0 \%$ (74) son varones y $17,0 \%(42)$ mujeres, con diferencia significativa ( $U=5158.000, p=.000)$. En relación con la edad, se identificó el mismo nivel de logro de la competencia en mención y de mayor frecuencia está de 41 a 50 años de edad (19,0\%), habiendo diferencia significativa $(H=20.025, p=.000)$. De la condición laboral se encontró que en docentes con nombramiento $(24,7 \%)$ y con contrato $(22,3 \%)$ prevalece un logro en proceso, existiendo diferencia significativa $(\mathrm{U}=6512.500, p=.035)$.

En cuanto a la competencia digital 7 (Tabla 3), el 36,8\% (91) de docentes tiene logro en proceso. Cuando analizamos por sexo el $22,7 \%$ (56) de varones tiene logro en proceso y el $14,6 \%$ (36) de mujeres logro insatisfactorio, habiendo diferencia significativa $(U=5393.500, p=.002)$. En relación con la edad se evidencia el logro en proceso, siendo más frecuente de 41 a 50 años de edad (17,4\%), habiendo diferencia significativa $(H=21.012, p=.000)$. De la variable condición laboral se identificó que $19.4 \%$ (48) de docentes con nombramiento tiene logro en proceso y del $18,6 \%$ (46) de docentes contratados logro satisfactorio, habiendo diferencia significativa $(\mathrm{U}=6348.000, p=.017)$.

De la competencia digital 8 (Tabla 3), el 51,0\% (126) de docentes presentan logro en proceso, $31,6 \%$ (78) son varones y $19,4 \%$ (48) mujeres, existiendo diferencia significativa (U= $5832.000, p=.017)$. En relación con la edad, prevalece logro en proceso, con mayor frecuencia de 41 a 50 años de edad (19,8\%), habiendo diferencia significativa ( $H=15.624, p=.001)$. De la condición laboral en docentes con nombramiento $(27,1 \%)$ y con contrato $(23,9 \%)$ prevalece el logro en proceso, existiendo diferencia significativa $(U=6380.500, p=.016)$.

De la competencia digital 9 (Tabla 3), el 49,4\% (122) de docentes presenta logro en proceso, $30,0 \%$ (74) son varones y $19,4 \%$ (48) mujeres, existiendo diferencia significativa (U= $5217.500, p=.000$ ). En relación con la edad, prevalece el logro en proceso con mayor frecuencia de 41 a 50 años (20,2\%), habiendo diferencia significativa $(H=21.592, p=.000)$. De la variable condición laboral se encontró que en docentes con nombramiento $(26,7 \%)$ y con contrato $(22,7 \%)$ prevalece el logro en proceso, existiendo diferencia significativa $(U=6584.000, p=.045)$.

Analizando a nivel de área el 56,3\% (139) de docentes están en proceso de desarrollar el área de competencia digital docente referido a comunicación y colaboración. 
Tabla 4: Área de competencia digital docente de creación de contenidos digitales

\begin{tabular}{|c|c|c|c|c|c|c|c|}
\hline & \multirow{2}{*}{\multicolumn{2}{|c|}{ Área de competencia 3}} & Insatisfactorio & En proceso & Satisfactorio & Destacado & \multirow{2}{*}{$p$} \\
\hline & & & $f(\%)$ & $f(\%)$ & $f(\%)$ & $f(\%)$ & \\
\hline \multirow{9}{*}{ 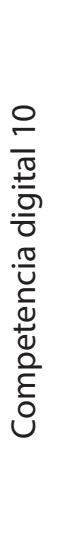 } & \multirow{2}{*}{ Sexo } & Varón & $11(4.5)$ & $58(23.5)$ & $76(30.8)$ & $14(5.7)$ & \multirow{2}{*}{.003} \\
\hline & & Mujer & $11(4.5)$ & $44(17.8)$ & $29(11.7)$ & $4(1.6)$ & \\
\hline & \multirow{4}{*}{ Edad } & $20-30$ & $0(0.0)$ & $6(2.4)$ & $4(1.6)$ & $1(0.4)$ & \multirow{4}{*}{.024} \\
\hline & & $31-40$ & $5(2.0)$ & $26(10.5)$ & $34(13.8)$ & $9(3.6)$ & \\
\hline & & $41-50$ & $11(4.5)$ & $34(13.8)$ & $47(19.0)$ & $7(2.8)$ & \\
\hline & & $>50$ & $6(2.4)$ & $36(14.6)$ & $20(8.1)$ & $1(0.4)$ & \\
\hline & \multirow{2}{*}{ Condición laboral } & Nombrado & $11(4.5)$ & $52(21.1)$ & 48(19.4) & $8(3.2)$ & \multirow{2}{*}{.436} \\
\hline & & Contratado & $11(4.5)$ & $50(20.2)$ & $57(23.1)$ & $10(4.0)$ & \\
\hline & \multicolumn{2}{|c|}{ Total CD10 } & $22(8.9)$ & $102(41.3)$ & $105(42.5)$ & $18(7.3)$ & \\
\hline \multirow{9}{*}{ 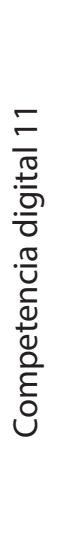 } & \multirow{2}{*}{ Sexo } & Varón & $12(4.9)$ & $74(30.0)$ & $67(27.1)$ & $6(2.4)$ & \multirow{2}{*}{.002} \\
\hline & & Mujer & $17(6.9)$ & $46(18.6)$ & $22(8.9)$ & $3(1.2)$ & \\
\hline & \multirow{4}{*}{ Edad } & $20-30$ & $0(0.0)$ & $5(2.0)$ & $5(2.0)$ & $1(0.4)$ & \multirow{4}{*}{.011} \\
\hline & & $31-40$ & $6(2.4)$ & $32(13.0)$ & $33(13.4)$ & $3(1.2)$ & \\
\hline & & $41-50$ & $9(3.6)$ & $52(21.1)$ & $33(13.4)$ & $5(2.0)$ & \\
\hline & & $>50$ & $14(5.7)$ & $31(12.6)$ & $18(7.3)$ & $0(0.0)$ & \\
\hline & \multirow{2}{*}{ Condición laboral } & Nombrado & $16(6.5)$ & $61(24.7)$ & $37(15.0)$ & $5(2.0)$ & \multirow{2}{*}{.196} \\
\hline & & Contratado & $13(5.3)$ & $59(23.9)$ & $52(21.1)$ & $4(1.6)$ & \\
\hline & \multicolumn{2}{|c|}{ Total CD11 } & 29(11.7) & $120(48.6)$ & $89(36.0)$ & $9(3.6)$ & \\
\hline \multirow{9}{*}{ 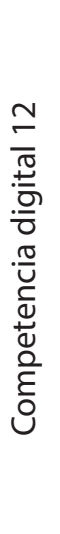 } & \multirow{2}{*}{ Sexo } & Varón & $18(7.3)$ & $80(32.4)$ & $53(21.5)$ & $8(3.2)$ & \multirow{2}{*}{.000} \\
\hline & & Mujer & $18(7.3)$ & $56(22.7)$ & $10(4.0)$ & $4(1.6)$ & \\
\hline & \multirow{4}{*}{ Edad } & $20-30$ & $2(0.8)$ & $6(2.4)$ & $2(0.8)$ & $1(0.4)$ & \multirow{4}{*}{.007} \\
\hline & & $31-40$ & $6(2.4)$ & $39(15.8)$ & $22(8.9)$ & $7(2.8)$ & \\
\hline & & $41-50$ & $12(4.9)$ & $56(22.7)$ & $28(11.3)$ & $3(1.2)$ & \\
\hline & & $>50$ & $16(6.5)$ & $35(14.2)$ & $11(4.5)$ & $1(0.4)$ & \\
\hline & \multirow{2}{*}{ Condición laboral } & Nombrado & $27(10.9)$ & $64(25.9)$ & $25(10.1)$ & $3(1.2)$ & \multirow{2}{*}{.001} \\
\hline & & Contratado & $9(3.6)$ & $72(29.1)$ & $38(15.4)$ & $9(3.6)$ & \\
\hline & \multicolumn{2}{|c|}{ Total CD12 } & $36(14.6)$ & $136(55.1)$ & $63(25.5)$ & $12(4.9)$ & \\
\hline
\end{tabular}


http://doi.org/10.15359/ree.25-3.34

\begin{tabular}{|c|c|c|c|c|c|c|c|}
\hline \multirow{2}{*}{\multicolumn{3}{|c|}{ Área de competencia 3}} & \multirow{2}{*}{$\begin{array}{c}\text { Insatisfactorio } \\
\mathbf{f}(\%)\end{array}$} & \multirow{2}{*}{$\begin{array}{c}\text { En proceso } \\
f(\%)\end{array}$} & \multirow{2}{*}{$\begin{array}{c}\text { Satisfactorio } \\
\mathbf{f}(\%)\end{array}$} & \multirow{2}{*}{$\begin{array}{c}\text { Destacado } \\
f(\%)\end{array}$} & \multirow{2}{*}{$\mathrm{p}$} \\
\hline & & & & & & & \\
\hline \multirow{9}{*}{ 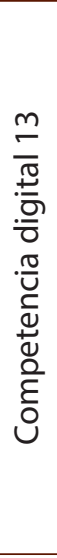 } & \multirow{2}{*}{ Sexo } & Varón & $35(14.2)$ & $80(32.4)$ & $36(14.6)$ & $8(3.2)$ & \multirow{2}{*}{.000} \\
\hline & & Mujer & $41(16.6)$ & $31(12.6)$ & $13(5.3)$ & $3(1.2)$ & \\
\hline & \multirow{4}{*}{ Edad } & $20-30$ & $3(1.2)$ & $4(1.6)$ & $3(1.2)$ & $1(0.4)$ & \multirow{4}{*}{.000} \\
\hline & & $31-40$ & $12(4.9)$ & $33(13.4)$ & $23(9.3)$ & $6(2.4)$ & \\
\hline & & $41-50$ & $30(12.1)$ & $46(18.6)$ & $19(7.7)$ & $4(1.6)$ & \\
\hline & & $>50$ & $31(12.6)$ & $28(11.3)$ & $4(1.6)$ & $0(0.0)$ & \\
\hline & \multirow{2}{*}{ Condición laboral } & Nombrado & $39(15.8)$ & $58(23.5)$ & $16(6.5)$ & $6(2.4)$ & \multirow{2}{*}{.150} \\
\hline & & Contratado & $37(15.0)$ & $53(21.5)$ & $33(13.4)$ & $5(2.0)$ & \\
\hline & \multicolumn{2}{|c|}{ Total CD13 } & $76(30.8)$ & $111(44.9)$ & 49(19.8) & $11(4.5)$ & \\
\hline \multirow{10}{*}{ 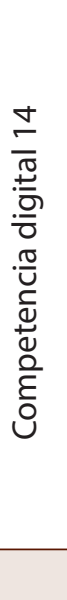 } & \multirow{2}{*}{ Sexo } & Varón & $6(2.4)$ & $56(22.7)$ & $84(34.0)$ & $13(5.3)$ & \multirow{2}{*}{.000} \\
\hline & & Mujer & $11(4.5)$ & $44(17.8)$ & $30(12.1)$ & $3(1.2)$ & \\
\hline & \multirow{4}{*}{ Edad } & $20-30$ & $1(0.4)$ & $4(1.6)$ & $6(2.4)$ & $0(0.0)$ & \multirow{4}{*}{.084} \\
\hline & & $31-40$ & $3(1.2)$ & $25(10.1)$ & $38(15.4)$ & $8(3.2)$ & \\
\hline & & $41-50$ & $7(2.8)$ & $40(16.2)$ & $48(19.4)$ & $4(1.6)$ & \\
\hline & & $>50$ & $6(2.4)$ & $31(12.6)$ & $22(8.9)$ & $4(1.6)$ & \\
\hline & \multirow{2}{*}{ Condición laboral } & Nombrado & $8(3.2)$ & $51(20.6)$ & $53(21.5)$ & $7(2.8)$ & \multirow{2}{*}{.537} \\
\hline & & Contratado & $9(3.6)$ & $49(19.8)$ & $61(24.7)$ & $9(3.6)$ & \\
\hline & \multicolumn{2}{|c|}{ Total CD14 } & $17(6.9)$ & $100(40.5)$ & $114(46.2)$ & $16(6.5)$ & \\
\hline & \multicolumn{2}{|c|}{ Total área de competencia 3} & $21(8.5)$ & 138(55.9) & $82(33.2)$ & $6(2.4)$ & \\
\hline
\end{tabular}

Nota: Competencia digital $10=$ Desarrollo de contenidos digitales. Competencia digital $11=$ Integración y reelaboración de contenidos digitales. Competencia digital $12=$ Derechos de autor y licencias. Competencia digital 13 = Programación. Competencia digital 14 = Integración curricular.

De la competencia digital 10 (Tabla 4), el 42,5\% (105) de docentes evidencia logro satisfactorio. Cuando analizamos por sexo el $30,8 \%$ (76) de varones presenta logro satisfactorio y el $17,8 \%$ (44) de mujeres logro en proceso, habiendo diferencia significativa ( $U=5531.500$, $p=.003)$. En relación con la edad, predomina el logro satisfactorio y de mayor frecuencia de 41 a 50 años de edad $(19,0 \%)$, con diferencia significativa $(H=9.471, p=.024)$. De la variable condición laboral el $21,1 \%$ (52) de docentes con nombramiento presenta logro en proceso y del $23,1 \%(57)$ de docentes con contrato logro satisfactorio, no hay diferencia significativa ( $U=$ $7212.500, p=.436)$. 
http://doi.org/10.15359/ree.25-3.34

http://www.una.ac.cr/educare

educare@una.ac.cr

En cuanto a la competencia digital 11 (Tabla 4), el 48,6\% (120) de docentes presenta logro en proceso, de quienes 30,0\% (74) son varones y 18,6\% (46) mujeres, con diferencia significativa $(\mathrm{U}=5453.000, p=.002)$. En relación con la edad, predomina el logro en proceso, siendo más frecuente de 41 a 50 años de edad (21,1\%), con diferencia significativa $(H=11.151, p=.011)$. Respecto a la condición laboral, en docentes con nombramiento $(24,7 \%)$ y con contrato $(23,9 \%)$ prevalece el logro en proceso, no existiendo diferencia significativa ( $U=6952.500, p=.196)$.

De la competencia digital 12 (Tabla 4), el 55,1\% (136) de docentes presenta logro en proceso, $32,4 \%(80)$ son varones y $22,7 \%$ (56) mujeres, existe diferencia significativa (U= $5275.000, p=.000)$. En relación con la edad, prevalece logro en proceso, con mayor frecuencia de 41 a 50 años de edad (22,7\%), habiendo diferencia significativa ( $H=11.999, p=.007)$. De la condición laboral en docentes con nombramiento $(25,9 \%)$ y con contrato $(29,1 \%)$ prevalece logro en proceso, existiendo diferencia significativa $(U=5872.000, p=.001)$.

De la competencia digital 13 (Tabla 4), el 44,9\% (111) de docentes presenta logro en proceso. Cuando analizamos por sexo el 32,4\% (80) de varones presenta logro en proceso y en el $16,6 \%(41)$ de mujeres un logro insatisfactorio, con diferencia significativa $(U=5236.500, p=$ .000). En relación con la edad, prevalece el logro en proceso con mayor frecuencia de 41 a 50 años $(18,6 \%)$, habiendo diferencia significativa $(H=26.634, p=.000)$. De la variable condición laboral se encontró que en docentes con nombramiento $(23,5 \%)$ y con contrato $(21,5 \%)$ prevalece el logro en proceso, no existiendo diferencia significativa $(U=6861.500, p=.150)$.

De la competencia digital 14 (Tabla 4), el 46,2\% (114) de docentes evidencia un logro satisfactorio. De la variable sexo el 34,0\% (84) de varones presenta un logro satisfactorio y en el $17,8 \%(44)$ de mujeres un logro en proceso, existe diferencia significativa $(U=5106.500, p=$ .000). En relación con la edad, prevalece el logro satisfactorio con mayor frecuencia de 41 a 50 años $(19,4 \%)$, no habiendo diferencia significativa $(H=6.653, p=.084)$. De la condición laboral en docentes con nombramiento $(21,5 \%)$ y con contrato $(24,7 \%)$ prevalece el logro satisfactorio, no existiendo diferencia significativa $(U=7299.500, p=.537)$.

Finalmente, el grupo de docentes presenta un nivel de logro satisfactorio en la competencia desarrollo de contenidos digitales e integración curricular; y un nivel de logro en proceso de las competencias integración y reelaboración de contenidos digitales, derechos de autoría y licencias, y programación. Analizando a nivel de área el 55,9\% (138) de docentes está en proceso de desarrollar el área de competencia digital docente, referida a la creación de contenidos digitales.

De la competencia digital 15 (Tabla 5), el 48,6\% (120) de docentes presenta un logro en proceso, $29,1 \%$ (72) son varones y $19,4 \%$ (48) mujeres, existiendo diferencia significativa (U= $5411.000, p=.001)$. En relación con la edad se evidencia el predominio de logro en proceso, siendo más frecuente de 41 a 50 años de edad (21,5\%), habiendo diferencia significativa $(\mathrm{H}=16.692, p=$ .001). De la condición laboral en docentes con nombramiento $(25,5 \%)$ y con contrato $(23,1 \%)$ prevalece un logro en proceso, no existiendo diferencia significativa $(U=6742.500, p=.092)$. 
Tabla 5: Área de competencia digital docente de seguridad

\begin{tabular}{|c|c|c|c|c|c|c|c|}
\hline & Ároa deromnoto & ia 4 & Insatisfactorio & En proceso & Satisfactorio & Destacado & $n$ \\
\hline & Area ue compete & & $f(\%)$ & $f(\%)$ & $f(\%)$ & $f(\%)$ & $\mathbf{r}$ \\
\hline & & Varón & 19(7.7) & $72(29.1)$ & $55(22.3)$ & $13(5.3)$ & \\
\hline & Jexu & Mujer & 19(7.7) & 48(19.4) & $18(7.3)$ & $3(1.2)$ & (0) \\
\hline$\frac{5}{\pi}$ & & $20-30$ & $0(0.0)$ & $6(2.4)$ & $4(1.6)$ & $1(0.4)$ & \\
\hline$\frac{\overline{7}}{0}$ & Fdad 2 a & $31-40$ & $6(2.4)$ & $30(12.1)$ & $30(12.1)$ & $8(3.2)$ & 001 \\
\hline : & Luan & $41-50$ & $16(6.5)$ & $53(21.5)$ & 24(9.7) & $6(2.4)$ & \\
\hline \pm & & $>50$ & $16(6.5)$ & $31(12.6)$ & $15(6.1)$ & $1(0.4)$ & \\
\hline$\varepsilon$ & Condición lahorl & Nombrado & $20(8.1)$ & $63(25.5)$ & $30(12.1)$ & $6(2.4)$ & 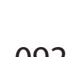 \\
\hline & 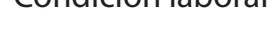 & Contratado & $18(7.3)$ & $57(23.1)$ & $43(17.4)$ & $10(4.0)$ & .0 \\
\hline & Total CL & & $38(15.4)$ & $120(48.6)$ & $73(29.6)$ & $16(6.5)$ & \\
\hline & & Varón & 29(11.7) & $77(31.2)$ & $46(18.6)$ & $7(2.8)$ & \\
\hline & sexu & Mujer & $24(9.7)$ & $51(20.6)$ & $10(4.0)$ & $3(1.2)$ & ב \\
\hline$\overline{\frac{\pi}{3}}$ & & $20-30$ & $1(0.4)$ & $6(2.4)$ & $3(1.2)$ & $1(0.4)$ & \\
\hline$\frac{\overline{7}}{0}$ & Edad 2 a & $31-40$ & $6(2.4)$ & $35(14.2)$ & $28(11.3)$ & $5(2.0)$ & O \\
\hline 䲶 & & $41-50$ & $28(11.3)$ & 49(19.8) & $18(7.3)$ & $4(1.6)$ & .000 \\
\hline 㫕 & & $>50$ & $18(7.3)$ & $38(15.4)$ & $7(2.8)$ & $0(0.0)$ & \\
\hline$\varepsilon$ & & Nombrado & $28(11.3)$ & $65(26.3)$ & $21(8.5)$ & $5(2.0)$ & \\
\hline & & Contratado & $25(10.1)$ & $63(25.5)$ & $35(14.2)$ & $5(2.0)$ & \\
\hline & Total CL & & $53(21.5)$ & $128(51.8)$ & $56(22.7)$ & $10(4.0)$ & \\
\hline & Covo & Varón & $10(4.0)$ & $61(24.7)$ & $79(32.0)$ & $9(3.6)$ & 172 \\
\hline & 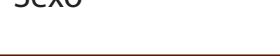 & Mujer & $7(2.8)$ & $43(17.4)$ & $32(13.0)$ & $6(2.4)$ & .120 \\
\hline$\frac{5}{5}$ & & $20-30$ & $0(0.0)$ & $8(3.2)$ & $2(0.8)$ & $1(0.4)$ & \\
\hline$\frac{\overline{7}}{0}$ & Fdad & $31-40$ & $2(0.8)$ & $26(10.5)$ & 41(16.6) & $5(2.0)$ & 050 \\
\hline : & & $41-50$ & $7(2.8)$ & $42(17.0)$ & $43(17.4)$ & $7(2.8)$ & \\
\hline 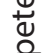 & & $>50$ & $8(3.2)$ & $28(11.3)$ & $25(10.1)$ & $2(0.8)$ & \\
\hline है & Condición laboral & Nombrado & $9(3.6)$ & $60(24.3)$ & $42(17.0)$ & $8(3.2)$ & 025 \\
\hline & & Contratado & $8(3.2)$ & $44(17.8)$ & 69(27.9) & $7(2.8)$ & S \\
\hline & Total CL & & $17(6.9)$ & 104(42.1) & $111(44.9)$ & $15(6.1)$ & \\
\hline
\end{tabular}


http://doi.org/10.15359/ree.25-3.34

http://www.una.ac.cr/educare

educare@una.ac.cr

\begin{tabular}{|c|c|c|c|c|c|c|c|}
\hline \multirow{2}{*}{\multicolumn{3}{|c|}{ Área de competencia 4}} & Insatisfactorio & En proceso & Satisfactorio & Destacado & \multirow{2}{*}{$\mathrm{p}$} \\
\hline & & & $f(\%)$ & $f(\%)$ & $f(\%)$ & $f(\%)$ & \\
\hline \multirow{8}{*}{ 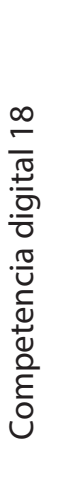 } & \multirow{2}{*}{ Sexo } & Varón & $14(5.7)$ & $62(25.1)$ & $79(32.0)$ & $4(1.6)$ & \multirow{2}{*}{.007} \\
\hline & & Mujer & $15(6.1)$ & $45(18.2)$ & $21(8.5)$ & $7(2.8)$ & \\
\hline & \multirow{4}{*}{ Edad } & $20-30$ & $1(0.4)$ & $3(1.2)$ & $6(2.4)$ & $1(0.4)$ & \multirow{4}{*}{.001} \\
\hline & & $31-40$ & $5(2.0)$ & $26(10.5)$ & $40(16.2)$ & $3(1.2)$ & \\
\hline & & $41-50$ & $10(4.0)$ & $45(18.2)$ & $38(15.4)$ & $6(2.4)$ & \\
\hline & & $>50$ & $13(5.3)$ & $33(13.4)$ & $16(6.5)$ & $1(0.4)$ & \\
\hline & \multirow{2}{*}{ Condición laboral } & Nombrado & $18(7.3)$ & $61(24.7)$ & $35(14.2)$ & $5(2.0)$ & \multirow{2}{*}{.001} \\
\hline & & Contratado & $11(4.5)$ & $46(18.6)$ & $65(26.3)$ & $6(2.4)$ & \\
\hline & \multicolumn{2}{|c|}{ Total CD18 } & $29(11.7)$ & 107(43.3) & $100(40.5)$ & $11(4.5)$ & \\
\hline & \multicolumn{2}{|c|}{ Total área de competencia 4} & $16(6.5)$ & $142(57.5)$ & $84(34.0)$ & $5(2.0)$ & \\
\hline
\end{tabular}

Nota: Competencia digital 15 = Protección de dispositivos. Competencia digital 16= Protección de datos personales e identidad digital. Competencia digital 17 = Protección de la salud. Competencia digital $18=$ Protección del entorno.

De la competencia digital 16 (Tabla 5), el 51,8\% (128) de docentes presenta un logro en proceso, $31,2 \%$ (77) son varones y $20,6 \%(51)$ mujeres, existiendo diferencia significativa (U= $5547.000, p=.003)$. En relación con la edad, prevalece el logro en proceso, con mayor frecuenta de 41 a 50 años de edad (19,8\%), habiendo diferencia significativa $(H=25.827, p=.000)$. De la condición laboral en docentes con nombramiento $(26,3 \%)$ y con contrato $(25,5 \%)$ prevalece el logro en proceso, no existiendo diferencia significativa $(U=6865.500, p=.144)$.

De la competencia digital 17 (Tabla 5), el 44,9\% (111) de docentes evidencia un logro satisfactorio. Cuando analizamos por sexo el $32,0 \%(79)$ de varones presenta un logro satisfactorio yel $17,4 \%$ (43) de mujeres un logro en proceso, no habiendo diferencia significativa $(U=6239.500$, $p=.123$ ). En relación con la edad, prevalece el logro satisfactorio con mayor frecuencia de 41 a 50 años $(17,4 \%)$, sin diferencia significativa $(H=7.807, p=.0501)$. De la variable condición laboral se identificó que $24,3 \%$ (60) de docentes con nombramiento tiene logro en proceso y el $27,9 \%$ (69) de docentes con contrato es satisfactorio, con diferencia significativa $(U=6465.000, p=.025)$.

De la competencia digital 18 (Tabla 5), el 43,3\% (107) de docentes evidencia un logro en proceso. De la variable sexo el 32,0\% (79) de varones presenta logro satisfactorio y en el $18,2 \%$ (45) de mujeres un logro en proceso, con diferencia significativa $(U=5654.500, p=.007)$. En relación con la edad, prevalece el logro en proceso con mayor frecuencia de 41 a 50 años $(18,2 \%)$, habiendo diferencia significativa $(H=16.261, p=.001)$. En la variable condición laboral el $24,7 \%$ 
(61) de docentes con nombramiento presenta logro en proceso y en el $26,3 \%$ (65) de docentes con contrato logro satisfactorio, habiendo diferencia significativa $(U=5930.500, p=.001)$.

Finalmente, el grupo de docentes presentan un nivel de logro satisfactorio en la competencia protección de la salud; y un nivel de logro en proceso de las competencias protección de dispositivos, protección de datos personales e identidad digital y protección del entorno. Analizando a nivel de área el 57,5\% (142) de docentes está en proceso de desarrollar el área de competencia digital docente referido a la seguridad.

Tabla 6: Área de competencia digital docente de resolución de problemas

\begin{tabular}{|c|c|c|c|c|c|c|c|}
\hline & Á mon do somnot & & Insatisfactorio & En proceso & Satisfactorio & Destacado & \\
\hline & агеa ve cumpere & & $f(\%)$ & $f(\%)$ & $f(\%)$ & $f(\%)$ & م \\
\hline & & Varón & $25(10.1)$ & $77(31.2)$ & $50(20.2)$ & $7(2.8)$ & \\
\hline & sexo & Mujer & $33(13.4)$ & $39(15.8)$ & $14(5.7)$ & $2(0.8)$ & . 000 \\
\hline & & $20-30$ & $1(0.4)$ & $6(2.4)$ & $3(1.2)$ & $1(0.4)$ & \\
\hline$\stackrel{a}{-}$ & & $31-40$ & $10(4.0)$ & $30(12.1)$ & $32(13.0)$ & $2(0.8)$ & \\
\hline 吾 & EUdu & $41-50$ & $30(12.1)$ & $46(18.6)$ & $18(7.3)$ & $5(2.0)$ & .002 \\
\hline . & & $>50$ & $17(6.9)$ & $34(13.8)$ & $11(4.5)$ & $1(0.4)$ & \\
\hline$\frac{c}{d}$ & Condición laborn & Nombrado & $34(13.8)$ & $56(22.7)$ & $25(10.1)$ & $4(1.6)$ & 026 \\
\hline है & - & Contratado & 24(9.7) & $60(24.3)$ & $39(15.8)$ & $5(2.0)$ & (2) \\
\hline & Total C & & $58(23.5)$ & $116(47.0)$ & $64(25.9)$ & $9(3.6)$ & \\
\hline & Covo & Varón & $14(5.7)$ & $73(29.6)$ & $64(25.9)$ & $8(3.2)$ & ב007 \\
\hline & $J$ & Mujer & $17(6.9)$ & 47(19.0) & $21(8.5)$ & $3(1.2)$ & .002 \\
\hline & & $20-30$ & $1(0.4)$ & $5(2.0)$ & $4(1.6)$ & $1(0.4)$ & \\
\hline 오 & Edad & $31-40$ & $3(1.2)$ & $35(14.2)$ & $32(13.0)$ & $4(1.6)$ & 016 \\
\hline$\stackrel{\frac{\pi}{2}}{\frac{\pi}{7}}$ & & $41-50$ & $18(7.3)$ & $46(18.6)$ & $31(12.6)$ & $4(1.6)$ & \\
\hline$\frac{0}{4}$ & & $>50$ & $9(3.6)$ & $34(13.8)$ & $18(7.3)$ & $2(0.8)$ & \\
\hline 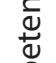 & Condición labrar & Nombrado & $16(6.5)$ & $61(24.7)$ & $37(15.0)$ & $5(2.0)$ & 303 \\
\hline है & & Contratado & $15(6.1)$ & $59(23.9)$ & $48(19.4)$ & $6(2.4)$ & \\
\hline & Total C & & $31(12.6)$ & $120(48.6)$ & $85(34.4)$ & $11(4.5)$ & \\
\hline
\end{tabular}

continúa 
http://doi.org/10.15359/ree.25-3.34

http://www.una.ac.cr/educare

educare@una.ac.cr

\begin{tabular}{|c|c|c|c|c|c|c|c|}
\hline & \multirow{2}{*}{\multicolumn{2}{|c|}{ Área de competencia 5}} & Insatisfactorio & En proceso & Satisfactorio & Destacado & \multirow{2}{*}{$p$} \\
\hline & & & $f(\%)$ & $f(\%)$ & $f(\%)$ & $f(\%)$ & \\
\hline \multirow{9}{*}{ 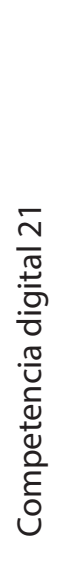 } & \multirow{2}{*}{ Sexo } & Varón & $20(8.1)$ & $68(27.5)$ & $64(25.9)$ & $7(2.8)$ & \multirow{2}{*}{.012} \\
\hline & & Mujer & $22(8.9)$ & $38(15.4)$ & $25(10.1)$ & $3(1.2)$ & \\
\hline & \multirow{4}{*}{ Edad } & $20-30$ & $1(0.4)$ & $4(1.6)$ & $6(2.4)$ & $0(0.0)$ & \multirow{4}{*}{.003} \\
\hline & & $31-40$ & $7(2.8)$ & 29(11.7) & $32(13.0)$ & $6(2.4)$ & \\
\hline & & $41-50$ & $17(6.9)$ & $43(17.4)$ & $36(14.6)$ & $3(1.2)$ & \\
\hline & & $>50$ & $17(6.9)$ & $30(12.1)$ & $15(6.1)$ & $1(0.4)$ & \\
\hline & \multirow{2}{*}{ Condición laboral } & Nombrado & $21(8.5)$ & $58(23.5)$ & $36(14.6)$ & $4(1.6)$ & \multirow{2}{*}{.105} \\
\hline & & Contratado & $21(8.5)$ & $48(19.4)$ & $53(21.5)$ & $6(2.4)$ & \\
\hline & \multicolumn{2}{|c|}{ Total CD21 } & $42(17.0)$ & $106(42.9)$ & $89(36.0)$ & $10(4.0)$ & \\
\hline \multirow{9}{*}{ 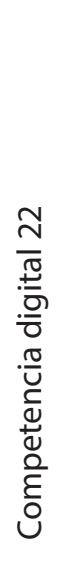 } & \multirow{2}{*}{ Sexo } & Varón & 19(7.7) & $66(26.7)$ & $65(26.3)$ & $9(3.6)$ & \multirow{2}{*}{.000} \\
\hline & & Mujer & $26(10.5)$ & $40(16.2)$ & $18(7.3)$ & $4(1.6)$ & \\
\hline & \multirow{4}{*}{ Edad } & $20-30$ & $1(0.4)$ & $5(2.0)$ & $4(1.6)$ & $1(0.4)$ & \multirow{4}{*}{.001} \\
\hline & & $31-40$ & $9(3.6)$ & $28(11.3)$ & $30(12.1)$ & $7(2.8)$ & \\
\hline & & $41-50$ & $14(5.7)$ & $46(18.6)$ & $36(14.6)$ & $3(1.2)$ & \\
\hline & & $>50$ & $21(8.5)$ & $27(10.9)$ & $13(5.3)$ & $2(0.8)$ & \\
\hline & \multirow{2}{*}{ Condición laboral } & Nombrado & $24(9.7)$ & $57(23.1)$ & $34(13.8)$ & $4(1.6)$ & \multirow{2}{*}{.043} \\
\hline & & Contratado & $21(8.5)$ & $49(19.8)$ & 49(19.8) & $9(3.6)$ & \\
\hline & \multicolumn{2}{|c|}{ Total CD22 } & $45(18.2)$ & $106(42.9)$ & $83(33.6)$ & $13(5.3)$ & \\
\hline & \multicolumn{2}{|c|}{ Total área de competencia 5} & $21(8.5)$ & $146(59.1)$ & $75(30.4)$ & $5(2.0)$ & \\
\hline
\end{tabular}

Nota: Competencia digital 19 = Resolución de problemas técnicos. Competencia digital $20=$ Identificación de necesidades y respuestas tecnológicas. Competencia digital 21 = Innovación y uso de la tecnología digital de forma creativa. Competencia digital 22 = Identificación de lagunas en la competencia digital.

De la competencia digital 19 (Tabla 6), el 47,0\% (116) de docentes presenta logro en proceso, $31,2 \%$ (77) son varones y $15,8 \%$ (39) mujeres, existe diferencia significativa (U= $4978.000, p=.000$ ). En relación con la edad se evidencia logro en proceso, siendo más frecuente de 41 a 50 años de edad (18,6\%), con diferencia significativa $(H=15.245, p=.002)$. En la variable condición laboral en docentes con nombramiento $(22,7 \%)$ y con contrato $(24,3 \%)$ prevalece logro en proceso, con diferencia significativa $(U=6521.500, p=.036)$. 
http://doi.org/10.15359/ree.25-3.34

De la competencia digital 20 (Tabla 6), el 48,6\% (120) de docentes presenta un logro en proceso, $29,6 \%$ (73) son varones y $19,0 \%$ (47) mujeres, con diferencia significativa (U=5456.500, $p=.002$ ). En relación con la edad, prevalece logro en proceso, con mayor frecuencia de 41 a 50 años de edad (18,6\%), habiendo diferencia significativa $(H=7.995, p=.046)$. En la condición laboral en docentes con nombramiento $(24,7 \%)$ y con contrato $(23,9 \%)$ prevalece logro en proceso, sin diferencia significativa $(U=7085.500, p=.303)$.

De la competencia digital 21 (Tabla 6), el 42,9\% (106) de docentes evidencia logro en proceso, $27,5 \%$ (68) son varones y $15,4 \%$ (38) mujeres, habiendo diferencia significativa $(U=5738.500, p=.012)$. En relación con la edad, prevalece logro en proceso con mayor frecuencia de 41 a 50 años (17,4\%), con diferencia significativa $(\mathrm{H}=14.054, p=.003)$. En la variable condición laboral se identificó que $23,5 \%$ (58) de docentes con nombramiento tiene un logro en proceso y del $21,5 \%$ (53) de docentes con contrato un logro satisfactorio, sin diferencia significativa ( $U=6768.500, p=.105)$.

De la competencia digital 22 (Tabla 6), el 42,9\% (106) de docentes evidencia logro en proceso, $26,7 \%$ (66) son varones y $16,2 \%$ (40) mujeres, con diferencia significativa ( $U=5060.500$, $p=.000$ ). En relación con la edad, presentan logro en proceso con mayor frecuencia de 41 a 50 años $(18,6 \%)$, habiendo diferencia significativa $(H=15.518, p=.001)$. En la variable condición laboral en docentes con nombramiento $(23,1 \%)$ y con contrato $(19,8 \%)$ prevalece logro en proceso, existiendo diferencia significativa $(U=6552.500, p=.043)$.

A nivel de área el 59,1\% (146) de docentes está en proceso de desarrollar el área de competencia digital docente referido a la resolución de problemas.

Tabla 7: Competencia digital docente en general

\begin{tabular}{|c|c|c|c|c|c|c|}
\hline \multirow{2}{*}{\multicolumn{2}{|c|}{$\begin{array}{c}\text { Competencia digital docente en } \\
\text { general }\end{array}$}} & \multirow{2}{*}{$\begin{array}{c}\text { Insatisfactorio } \\
\mathrm{f}(\%)\end{array}$} & \multirow{2}{*}{$\begin{array}{c}\text { En proceso } \\
f(\%)\end{array}$} & \multirow{2}{*}{$\begin{array}{c}\text { Satisfactorio } \\
\mathbf{f}(\%)\end{array}$} & \multirow{2}{*}{$\begin{array}{c}\text { Destacado } \\
\mathbf{f}(\%)\end{array}$} & \multirow{2}{*}{$p$} \\
\hline & & & & & & \\
\hline \multirow{2}{*}{ Sexo } & Varón & $9(3.6)$ & $83(33.6)$ & $65(26.3)$ & $2(0.8)$ & \multirow{2}{*}{.001} \\
\hline & Mujer & $9(3.6)$ & $62(25.1)$ & $14(5.7)$ & $3(1.2)$ & \\
\hline \multirow{4}{*}{ Edad } & $20-30$ & $0(0.0)$ & $7(2.8)$ & $3(1.2)$ & $1(0.4)$ & \multirow{4}{*}{.000} \\
\hline & $31-40$ & $1(0.4)$ & $34(13.8)$ & $37(15.0)$ & $2(0.8)$ & \\
\hline & $41-50$ & $8(3.2)$ & $62(25.1)$ & $27(10.9)$ & $2(0.8)$ & \\
\hline & $>50$ & $9(3.6)$ & $42(17.0)$ & $12(4.9)$ & $0(0.0)$ & \\
\hline \multirow{2}{*}{ Condición laboral } & Nombrado & $12(4.9)$ & $77(31.2)$ & $28(11.3)$ & $2(0.8)$ & \multirow{2}{*}{.003} \\
\hline & Contratado & $6(2.4)$ & $68(27.5)$ & $51(20.6)$ & $3(1.2)$ & \\
\hline \multicolumn{2}{|c|}{ Total } & $18(7.3)$ & $145(58.7)$ & $79(32.0)$ & $5(2.0)$ & \\
\hline
\end{tabular}

Nota: Elaboración propia. 
http://doi.org/10.15359/ree.25-3.34

http://www.una.ac.cr/educare

educare@una.ac.cr

De la competencia digital en general, el 58,7\% (145) de docentes está en proceso de desarrollo, de este grupo 33,6\% (83) son varones y 25,1\% (62) mujeres, habiendo diferencia significativa $(U=5388.500, p=.001)$. En relación con la edad, prevalece el nivel de logro en proceso con mayor frecuencia de 41 a 50 años (25,1\%), con diferencia significativa $(H=22.915$, $p=.000)$. De la condición laboral se encontró que en docentes con nombramiento $(31,2 \%)$ y con contrato $(27,5 \%)$ prevalece el logro de competencia digital en proceso, con diferencia significativa $(\mathrm{U}=6155.000, p=.003)$.

\section{Discusión}

El estudiantado en el contexto actual posiblemente haya desarrollado competencias digitales sin orientación alguna, a la vez interactúan con docentes que presentan limitaciones respecto a ello. Entonces, si el personal docente no ha desarrollado competencias digitales para incorporarlas en su práctica pedagógica o presenta dificultades, pues no se estaría cumpliendo la relación didáctica docente-estudiante y, por tanto, podría generar problemas cuando el estudiantado media con las TIC. Ello nos motivó a analizar el nivel de logro de las diferentes áreas de competencia digital docente según sexo, edad y condición laboral a la vez que, en el contexto del Perú, en especial el de la región central, no existen estudios al respecto.

Cuando analizamos el área de información y alfabetización informacional, en la CD de navegación, búsqueda y filtrado de información, datos y contenidos digitales, el 50,2\% de docentes presenta un nivel de logro satisfactorio, resultado que coincide con otros estudios (Falcó Boudet, 2017; Mortis Lozoya et al., 2013). La CD de evaluación de información, datos y contenidos digitales (47,0\%) está en un nivel de logro en proceso y no concuerda con el estudio de Falcó Boudet (2017). La CD almacenamiento y recuperación de información, datos y contenidos digitales $(45,7 \%)$ presenta mayor frecuencia en el logro de proceso, dichos resultados concuerdan con los de Falcó Boudet (2017).

En cuanto al área comunicación y colaboración, la CD de interacción mediante las tecnologías digitales (44,1\%) presenta logro en proceso, este resultado no concuerda con los de Falcó Boudet (2017) quien encontró un nivel competencial alto, pero sí concuerda con el estudio de García-Pérez et al. (2016). La CD compartir información y contenidos digitales (45,3\%), que también presenta logro en proceso, no concuerda con González Rivallo y Gutiérrez Martín (2017). De la CD participación ciudadana en línea $(47,0 \%)$ con logro en proceso no se encontraron estudios al respecto. La CD colaboración mediante canales digitales (36,0\%), que tiene logro en proceso, tampoco concuerda con el estudio de González Rivallo y Gutiérrez Martín (2017). La CD netiqueta $(51,0 \%)$ está en proceso y no coincide con Falcó Boudet (2017) quien señala que el $65 \%$ no sabe qué es o no sabe cómo utilizarla. Y CD gestión de la identidad digital $(49,4 \%)$ que también está en proceso tampoco concuerda con Falcó Boudet (2017) porque señala que el $75,35 \%$ presenta un nivel alto.

\footnotetext{
20 Jhon Richard Orosco-Fabian, Rocío Pomasunco-Huaytalla, Wilfredo Gómez-Galindo, Edwin Salgado-Samaniego y Deysi Alina Colachagua-Calderón 
http://doi.org/10.15359/ree.25-3.34

Referente al área creación de contenidos digitales, en la CD desarrollo de contenidos digitales $(42,5 \%)$ que presenta un logro satisfactorio, coincide con el estudio de Falcó Boudet (2017) mas no con el estudio de Mortis Lozoya et al. (2013). En la CD integración curricular $(46,2 \%)$ que también presenta logro satisfactorio no coincide con el estudio de González Rivallo y Gutiérrez Martín (2017). De las CD integración y reelaboración de contenidos digitales (48,6\%) y programación (44,9\%) que evidencia un logro en proceso no se encontraron estudios para el análisis. De la CD derechos de autoría y licencias (55,1\%) que presenta logro en proceso no coincide con el estudio de Falcó Boudet (2017), ya que el nivel competencial del personal docente en su estudio es bajo y en el caso de Mortis Lozoya et al. (2013) resulta competente.

Del área seguridad, la CD protección de la salud (44,9\%) se presenta con mayor frecuencia en el nivel de logro satisfactorio, resultado que no coincide con el de González Rivallo y Gutiérrez Martín (2017), quienes señalan que alrededor del 80\% de docentes no conoce sobre riesgos derivados del uso de las TIC como el ciberbullying y similares. La CD de protección de dispositivos (48,6\%) que presenta logro en proceso concuerda con Falcó Boudet (2017). La CD protección de datos personales e identidad digital (51,8\%) que también presenta logro en proceso no concuerda con el estudio de Falcó Boudet (2017) donde el 80,33\% es capaz de hacerlo sin ayuda. Y la CD protección del entorno (43,3\%) que evidencia logro en proceso no coincide con los resultados de Falcó Boudet (2017, p. 78) quien señala que "un 67\% se preocupa por proteger el medio ambiente reciclando componentes y equipos".

En cuanto al área de resolución de problemas, la CD de resolución de problemas técnicos (47,0\%) que presenta logro en proceso no concuerda con el de Falcó Boudet (2017) quien señala que $73,68 \%$ es capaz de resolver este tipo de problemas. La CD identificación de lagunas en la competencia digital (42,9\%) que también presenta logro en proceso coincide con el estudio de Pozuelo Echegaray (2014). Asimismo, las CD identificación de necesidades y respuestas tecnológicas $(48,6 \%)$ e innovación y uso de la tecnología digital de forma creativa $(42,9 \%)$ también presentan logro en proceso, pero no se encontraron estudios para su discusión.

A nivel general, el 58,7\% de docentes posee un nivel de logro de las competencias digitales en proceso. Resultado que no coincide con el estudio Hernández Suárez et al. (2016) realizado en Colombia, quienes identificaron un nivel competente y muy competente. Pero sí presenta relación con el estudio de Guizado Osco et al. (2019), quienes hallaron en la capital del Perú que predomina un nivel regular de competencias digitales en el personal docente.

Es sabido que estos cambios tecnológicos impactan en los escenarios educativos, por tanto, se requiere de estrategias pedagógicas y didácticas orientadas a aprovechar los soportes digitales. Por ello, Moreno-Guerrero et al. (2019) confirman la necesidad de capacitar 
http://doi.org/10.15359/ree.25-3.34

http://www.una.ac.cr/educare

educare@una.ac.cr

al personal docente en este aspecto, para ello las autoridades deben diseñar planes de formación apropiados. El personal docente, en su mayoría, es consciente de las ventajas de las TIC, sin embargo, rara vez supervisa el uso pertinente en el estudiantado, y menos busca orientación de personas expertas para mejorar el uso de las tecnologías (Rivera-Laylle et al., 2017). También Pozuelo Echegaray (2014) afirma que el personal docente requiere de un cambio necesario para incorporar las TIC, debe transformar, así, la metodología de enseñanza, reafirma que el reto no es dotar de infraestructura y equipamientos informáticos, sino la formación de capacidades para emplear las TIC. Además, Gisbert Cervera et al. (2016) enfatizan que para el estudiantado de hoy se requiere maestros y maestras competentes digitalmente y hace referencia a la Organización de las Naciones Unidas para la Educación, la Ciencia y la Cultura (UNESCO, 2008). También Pérez Escoda y Rodríguez Conde (2016) identificaron que el profesorado autopercibe una escasez de habilidades digitales para el uso pedagógico, lo que implica reconsiderar las políticas de formación en este campo. Por otro lado, no se puede dejar de lado el rol de las familias que, conjuntamente con el personal docente, incluyen las TIC en la comunicación, lo cual evidencia "que no solo se debe mejorar la formación de las familias, sino también la de los docentes, especialmente para reducir su resistencia a utilizarlas" (Macià Bordalba y Garreta Bochaca, 2018, pp. 239-240).

El estudio de las competencias digitales del personal docente es de interés para las instituciones educativas de todos los niveles, especialmente en el nivel secundario, ya que es allí donde se deben fortalecer las competencias digitales del estudiantado. Por tal motivo, se sugiere que, en futuras investigaciones, se aborden la formación de competencias digitales del personal docente, así como también la formulación de propuestas que conlleven a fortalecer las diferentes competencias digitales en docentes, estudiantes, padres y madres de familia.

Finalmente, después de analizar los resultados en las cinco áreas de competencia digital (información y alfabetización informacional, comunicación y colaboración, creación de contenidos digitales, seguridad y resolución de problemas) se concluye que más del $50 \%$ del personal docente está en proceso de desarrollo, asimismo, cuando se comparó los resultados en relación con el sexo, la edad y la condición laboral de los sujetos participantes se encontró que existen diferencias significativas. Y en cuanto a las 22 competencias digitales analizadas, el personal docente presenta un nivel de logro satisfactorio solo en cuatro de ellas: navegación, búsqueda y filtrado de información, datos y contenidos digitales; desarrollo de contenidos digitales, integración curricular y protección de la salud. Y en las demás competencias digitales prevalece el nivel de logro en proceso. 
http://doi.org/10.15359/ree.25-3.34

\section{Referencias}

Arbués, E., Ibarrola, S. y Magallón, S. (2014). Las competencias básicas en la formación inicial del profesorado de primaria. Una metodología transversal desde las didácticas específicas. Magister, 26(1) 34-42. https://doi.org/10.1016/S0212-6796(14)70016-7

Benítez Larghi, S., Lemus, M. y Welschinger Lascano, N. (2014). La inclusión masiva de tecnologías digitales en el ámbito escolar: Un estudio comparativo de la apropiación de TIC por estudiantes de clases populares y clases medias en el marco del Programa Conectar Igualdad en el Gran La Plata. Propuesta educativa, 23(42), 86-92. https://www.redalyc.org/ pdf/4030/403041713010.pdf

Castillo Obaco, J. S., Palta Valladares, N. I. y Sigüenza Orellana, J. P. (2016). Uso de pizarras digitales interactivas como recurso de enseñanza para los docentes. Magister, 28(2), 71-85. https:// doi.org/10.1016/j.magis.2016.11.001

Escorcia-Oyola, L. y Jaimes de Triviño, C. (2015). Tendencias de uso de las TIC en el contexto escolar a partir de las experiencias de los docentes. Educación y educadores, 18(1), 135-152. https://doi.org/10.5294/edu.2015.18.1.8

Falcó Boudet, J. M. (2017). Evaluación de la competencia digital docente en la Comunidad Autónoma de Aragón. Revista Electrónica de Investigación Educativa, 19(4), 73-83. https:// doi.org/10.24320/redie.2017.19.4.1359

Fernández-Cruz, F.-J. y Fernández-Díaz, M. J. (2016). Los docentes de la generación Z y sus competencias digitales. Comunicar, 24(46), 97-105. https://doi.org/10.3916/C46-2016-10

García-Pérez, R., Rebollo-Catalán, Á. y García-Pérez, C. (2016). Relación entre las preferencias de formación del profesorado y su competencia digital en las redes sociales. Bordón Revista de Pedagogía, 68(2), 137-153. https://doi.org/10.13042/Bordon.2016.68209

Gisbert Cervera, M., González Martínez, J. y Esteve Mon, F. (2016). Competencia digital y competencia digital docente: Una panorámica sobre el estado de la cuestión. Revista Interuniversitaria de Investigación en Tecnología Educativa (RIITE), (0), 74-83. https://doi. org/10.6018/riite/2016/257631

González Rivallo, R. y Gutiérrez Martín, A. (2017). Competencias mediática y digital del profesorado e integración curricular de las tecnologías digitales. Revista Fuentes, 19(2), 5767. https://revistascientificas.us.es/index.php/fuentes/article/view/4028

Guizado Osco, F., Menacho Vargas, I. y Salvatierra Melgar, A. (2019). Competencia digital y desarrollo profesional de los docentes de dos instituciones de educación básica regular del distrito de Los Olivos, Hamut'ay, 6(1), 54-70. https://doi.org/10.21503/hamu.v6i1.1574 
http://doi.org/10.15359/ree.25-3.34

http://www.una.ac.cr/educare

educare@una.ac.cr

Hernández Nieto, R. (2011). Instrumentos de recolección de datos en ciencias sociales y ciencias biomédicas. Universidad de Los Andes.

Hernández Suárez, C. A., Arévalo Duarte, M. A. y Gamboa Suárez, A. A. (2016). Competencias TIC para el desarrollo profesional docente en educación básica. Praxis \& Saber, 7(14), 41-69. https://doi.org/10.19053/22160159.5217

Instituto Nacional de Tecnologías Educativas y de Formación del Profesorado. (2017). Marco común de competencia digital docente. Ministerio de Educación, Cultura y Deporte. https:// aprende.intef.es/sites/default/files/2018-05/2017 1020 Marco-Com\%C3\%BAn-deCompetencia-Digital-Docente.pdf

Macià Bordalba, M. y Garreta Bochaca, J. (2018). Accesibilidad y alfabetización digital: Barreras para la integración de las TIC en la comunicación familia/escuela. Revista de Investigación Educativa, 36(1), 239-257.https://doi.org/10.6018/rie.36.1.290111

Ministerio de Educación. (2017). Rúbricas de observación de aula para la evaluación del desempeño docente. Autor. https://es.slideshare.net/kathycarbajal52/rubricas-de-observacin-deaula-para-la-evaluacin-del-desempeo-docente

Moreno-Guerrero, A., Miaja-Chippirraz, N., Bueno-Pedrero, A. y Borrego-Otero, L. (2019). El área de información y alfabetización informacional de la competencia digital docente. Zenodo. https://doi.org/10.5281/zenodo.3344532

Mortis Lozoya, S., Valdés Cuervo, A., Angulo Armenta, J., García López, R. I. y Cuevas Salazar, O. (2013). Competencias digitales en docentes de educación secundaria. Municipio de un Estado del Noroeste de México. Perspectiva Educacional, Formación de Profesores, 52(2), 135-153. https://doi.org/10.4151/07189729-Vol.52-Iss.2-Art.174

Organización de las Naciones Unidas para la Educación, la Ciencia y la Cultura. (2008). Estándares de competencia TIC para docentes. Autor.

Pérez Escoda, A. y Rodríguez Conde, M. J. (2016). Evaluación de las competencias digitales autopercibidas del profesorado de educación primaria en Castilla y León. Revista de Investigación Educativa, 34(2), 399-415. http://dx.doi.org/10.6018/rie.34.2.215121

Pinto Santos, A. R., Díaz Carreño, J. y Alfaro Camargo, C. (2016). Modelo espiral de competencias docentes TICTACTEP aplicado al desarrollo de competencias digitales. Revista Educativa Hekademos. 9(19), 39-48. https://dialnet.unirioja.es/servlet/articulo?codigo=6280715 
http://doi.org/10.15359/ree.25-3.34

Pozuelo Echegaray, J. (2014). ¿Y si enseñamos de otra manera? Competencias digitales para el cambio metodológico. Caracciolos. Revista digital de investigación en docencia, 2(1), 1-21. https://ebuah.uah.es/dspace/bitstream/handle/10017/20848/ense\%C3\%B1amos Pozuelo_CARACCIOLOS 2014_N2.pdf?sequence=1\&isAllowed=y

Rangel Baca, A. (2015). Competencias docentes digitales: Propuesta de un perfil. Píxel-Bit. Revista de Medios y Educación, (46), 235-248. https://doi.org/10.12795/pixelbit.2015.i46.15

Rivera-Laylle, L. I., Fernández-Morales, K., Guzmán-Games, F. J. y Eduardo-Pulido, J. E. (2017). La aceptación de las TIC por profesorado universitario: Conocimiento, actitud y practicidad. Revista Electrónica Educare, 21(3), 1-18. https://doi.org/10.15359/ree.21-3.6

Román, M. y Murillo, F. J. (2014). Disponibilidad y uso de TIC en escuelas latinoamericanas: Incidencia en el rendimiento escolar. Educação e Pesquisa, 40(4), 879-895. https://doi. org/10.1590/s1517-97022014121528

Sandoval Rubilar, P., Rodriguez Alveal, F. y Maldonado Fuentes, A. C. (2017). Evaluación de la alfabetización digital y pedagógica en TIC, a partir de las opiniones de estudiantes en Formación Inicial Docente. Educação e Pesquisa, 43(1),127-143. https://doi.org/10.1590/ $\underline{\text { s1517-9702201701154907 }}$

Talanquer, V. (2009). De escuelas, docentes y TICs. Educación química, 20(3). 345-350. https://doi. org/10.1016/S0187-893X(18)30035-1

Vargas D’Uniam, J., Chumpitaz-Campos, L., Suárez-Díaz, G. y Badia, A. (2014). Relación entre las competencias digitales de docentes de educación básica y el uso educativo de las tecnologías en las aulas. Profesorado. Revista de currículum y formación del profesorado, 18(3), 361-377. https://recyt.fecyt.es/index.php/profesorado/article/view/41213

Vivancos, J. (2008). Tratamiento de la información y competencia digital. Alianza Editorial. 